\title{
Recent Progresses of Mesophase Pitch A Review at a Receipt of 1993 Charles E. Pettinos Award, American Carbon Society
}

\author{
Isao Mochida \\ Kyushu University \\ 6-1 Kasuga-koen, Kasuga-shi 816, Japan
}

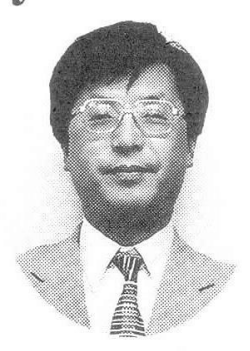

\section{Introduction}

The American Carbon Society selected me a recipient of 1993 Charles E. Pettinos Award at the 21th American Carbon Conference, Buffalo. The Award has been presented to 12 internationally distinguished scientists in 1969 - 1993 as listed in Table 1 because of their "recent outstanding accomplishment in the science and/or technology of carbon material". My recent achievement on synthesis, structure, properties and application of mesophase pitches derived from aromatic hydrocarbons by the aid of $\mathrm{HF} / \mathrm{BF}_{3}$ is evaluated. It is my great honor since this award as well as the George Skakel Memorial Awards, another American Carbon Society Award, has been reputed as the highest reward in the international community of carbon science and technology.

I have been involved in the chemistry of mesophase since 1972 when the concept of mesophase had spread in our community. Since then, I have been fascinated by a variety of its aspects. A number of people in both academic and industrial fields of international community guide, assist and run together. My collaborators in Kyushu University and Mitsubishi Gas Chemical studied together the novel mesophase pitch of unique properties with both academic and industrial interests. The pitch is now distributed widely to be tested, analyzed, and evaluated in the field of carbon science and technology, stimulating broad areas of material science and technology. The commercial production of the mesophase pitch(AR pitch) is owing to Mr. M. Komatsu, S. Fujiyama, and Y. Sakai, and their research team at Mitsubishi Gas Chemical Co. I am particularly grateful to those people for their collaboration since I cannot accomplish without international acquaintance of the pitch.

Table 1 includes also awardees of George Skakel Memorial Award up to 1993. The two lists covered great names of leaders in the international carbon society. It is rather pity that we can find only name of Professor Noda in the list, because our activity has certainly been leading the international society.

I hope that our activity can be properly evaluated from now on. At the same time, I believe that our international cooperation should be more emphasized, claiming our genuine ideas, scientific soundness, and industrial practice on the bases of achievement accomplished by our pioneers.

In the present review, I will summarize recent progresses of mesophase pitch principally based on our recent achievement, including a short history of mesophase recognition, usefulness of its concept in the carbonization science and technology, preparation and synthesis of the mesophase pitch, its structural chemistry on the levels of molecules and molecular assembles, properties as a liquid crystal, sciences in the preparation and evaluation of carbon fibers derived from the mesophase pitch, and finally its future development aiming at the promising targets of material science and practical application. I will be very happy if I could 
Table 1(a) Recepients of Charles E. Pettinos and Geoge Skakel Memorial Awards of American Carbon Society.

\begin{tabular}{|c|c|c|c|}
\hline \multirow[b]{2}{*}{$\begin{array}{l}\text { los } \\
\text { omplishments } \\
\text { inology of }\end{array}$} & Year & Name & Subject \\
\hline & $\begin{array}{l}1969 \\
1971 \\
1973 \\
1975 \\
1977 \\
1979 \\
1981 \\
1983 \\
1985 \\
1987 \\
1989 \\
1991 \\
1993\end{array}$ & $\begin{array}{l}\text { J. M. Thomas } \\
\text { W. Watt } \\
\text { S. Ergun } \\
\text { J. C. Bokros } \\
\text { L. S. Singer } \\
\text { J. G. Hooley } \\
\text { B. T. Kelly } \\
\text { A. Oberlin } \\
\text { J. W. McClure } \\
\text { R. T. K. Baker } \\
\text { I. C. Lewis } \\
\text { J. Lahaye } \\
\text { I. Mochida }\end{array}$ & $\begin{array}{l}\text { Structure of Graphite } \\
\text { Carbon in Prosthetic Device } \\
\text { The Mesophase Pitch and High-Modulus } \\
\text { Carbon Fibers from Pitch } \\
\text { Intercalation of Layered Structures } \\
\text { Graphite - The Most Fascinating } \\
\text { Nuclear Material } \\
\text { Carbonization and Graphitization as } \\
\text { Studied by TEM } \\
\text { An Electron's Eye View of Carbon and } \\
\text { Graphite } \\
\text { Catalytic Growth of Carbon Material } \\
\text { The Fascinating Science of } \\
\text { Carbonization Chemistry } \\
\text { Particulate Carbon from the Gas Phase } \\
\text { The Formation, Separation, and } \\
\text { Characterization of Carbonaceous Materials } \\
\text { and in particular, His Recent Development } \\
\text { of Na and mNa-Based Mesophase }\end{array}$ \\
\hline
\end{tabular}

Table 1(b) Recepients of Charles E. Pettinos and Geoge Skakel Memorial Awards of American Carbon Society.

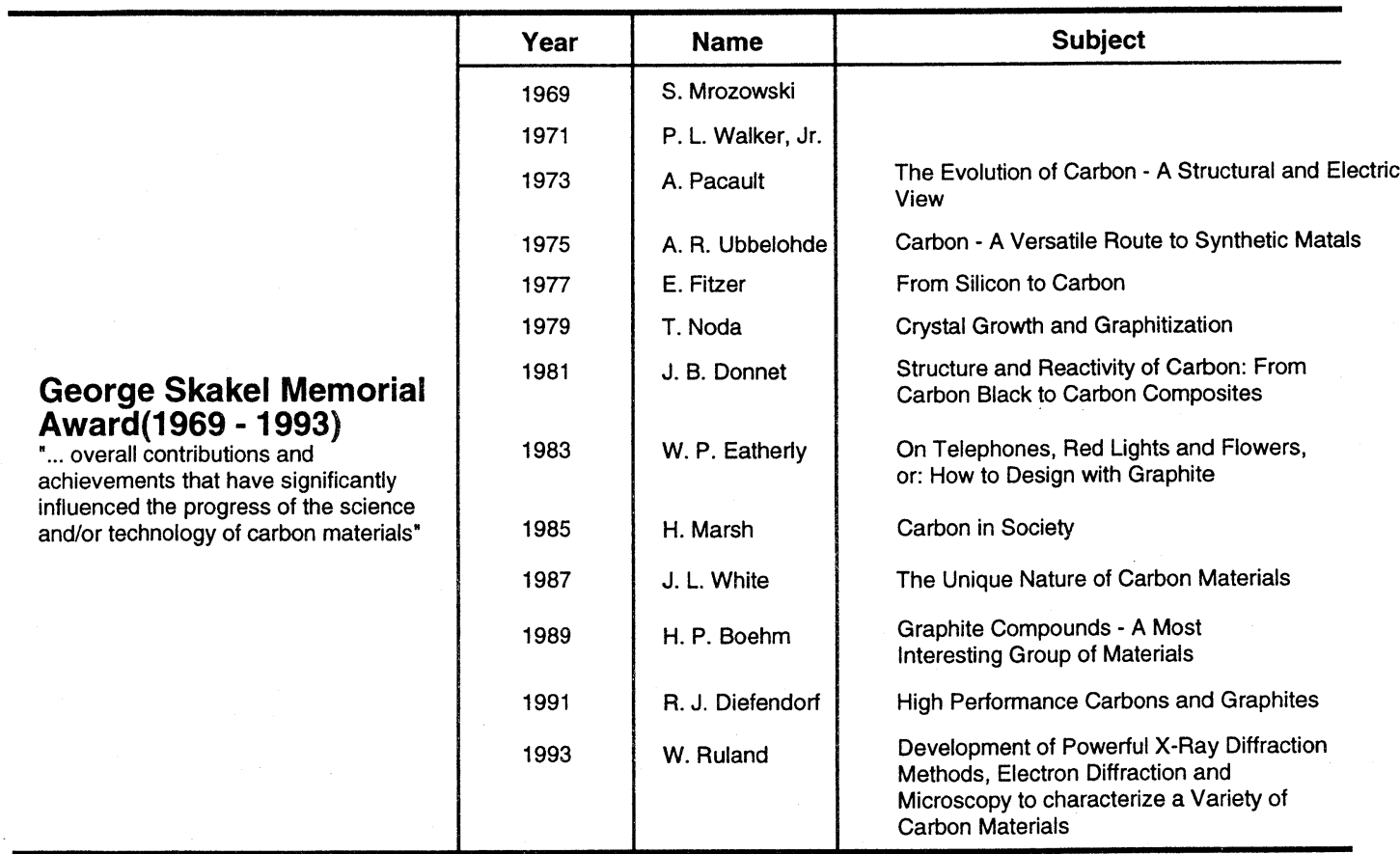


stimulate broad interest of our society in this unique material.

\section{Recognition of mesophase and mesophase pitch}

Brooks and Taylor found a carbonization scheme of coal and coal tar where the anisotropic spheres appear, grow and coalesce into a solid semi-coke of optical anisotropy ${ }^{1)}$. Such a semi-coke is more or less graphitizable, hence the optical anisotropy, while the coking substance is liquid, is a key to industrial carbons such as needle coke and blast furnace coke of bulk production. Such an intermediate state is called mesophase, which is defined as an intermediate for the graphitizable carbon.

To improve the quality of the carbon products, physical and organic chemistry of mesophase pitch has been studied rather extensively. Its recognition as a diskotic liquid crystal suggests how the mesophase can be formed and why it can be an intermediate for the graphitizable carbon.

Study of mesophase pitch itself as a material or its modification led to its application as a strategic substance for carbon materials of high performance. The substance looks like pitch, however because of its difference from the conventional pitch of optical isotropy, it is now called mesophase pitch or carbonaceous liquid crystal. Nevertheless, its components are not always liquid crystal. For example, particles isolated as quinoline insoluble are often hardly fusible alike semi-coke although they adhere each other into carbon artifact of high density when heated in their close packing.

The mesophase pitch has been found by Otani ${ }^{2)}$ and Singer ${ }^{3)}$ to be a precursor of high performance carbon fiber, while isotropic pitch is that of general performance. Mesophase pitch based carbon fibers commercialized by Union Carbide and now Amoco, are principally targeted for the space application because of its excellent stiffness.

Extensive research of mesophase pitch has been carried out after oil crisis until now because mesophase pitch carbon fiber can be a strategic material because excellent mechanical properties per weight and reasonable price are expected. So far its expectation is not fully realized yet. The mesophase pitches derived from pure aromatic hydrocarbons can solve basically some of the current problems, and further development is now strongly expected.

\section{Preparation of mesophase pitch}

Otani first prepared mesophase pitch intentionally as a precursor for the carbon fiber of high performance ${ }^{2}$. He carbonized tetrabenzophenazine, residue of cracked crude at very high temperature, and polyvinyl chloride by selecting carefully the temperature and time. Rather particular starting substances and mesophase pitch of poor spinning properties were noted. Acenaphthene is another example to give a mesophase pitch by conventional carbonization.

Singer ${ }^{3)}$ and his Union Carbide group introduced a commercial process of mesophase pitch preparation where petroleum pitch or residue was heat treated under rapid gas flow. The rapid gas flow which very efficiently removes lighter components in the feed to accelerate the induction of liquid crystal nature to the pitch. The mesophase pitch of low softening point and high solubility thus prepared, allowing commercial production of mesophase pitch based carbon fiber. Only heavier components are converted into the mesophase pitch by least extent of carbonization. A limited yields around $20 \sim 30 \%$ is inevitable, increasing the price of the product. The heat treatment under vacuum or two stage heat treatment under pressure in the first and vacuum in the second stage increased the yield significantly up to $50 \%{ }^{3 a)}$. Diefendorf ${ }^{4)}$ proposed isolation of mesophase pitch by removing with two solvents both lighter and heavier fractions in the heat treated pitch. The yield and properties are both controllable by heat treatment and extraction. Du. Pont applied this process for their fiber preparation. The yield was still low and properties control was limited.

Honda and Yamada proposed hydrogenation of coal $\operatorname{tar}$ before preparation of mesophase pitch ${ }^{5}$. Otherwise coal tar provided very unreactive mesophase pitch of high softening point. The present author and his groups suggest importance of methyl and naphthalene groups to control the solubility and softening point of the mesophase pitch $^{5 \mathrm{a})}$. However, additional problems are hydrogenation of high cost and further reduction of yield. Thus, the mesophase pitch had been costprohibitive and its variety had been restrictive based on 


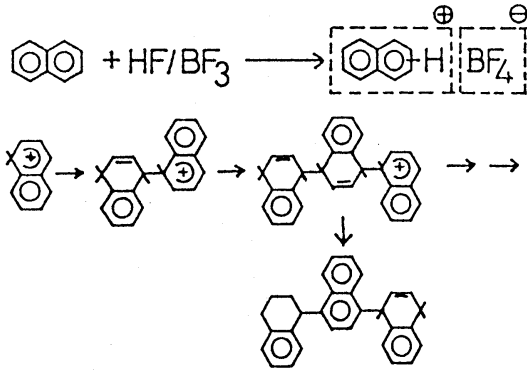

Fig.1 Catalytic condensation of aromatic hydrocarbon $\left(\mathrm{HF} / \mathrm{BF}_{3}\right.$ catalyst).

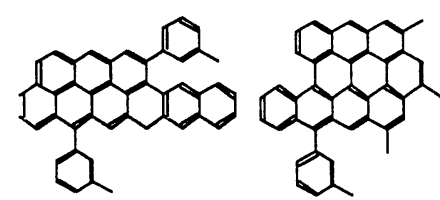

FCC-DO

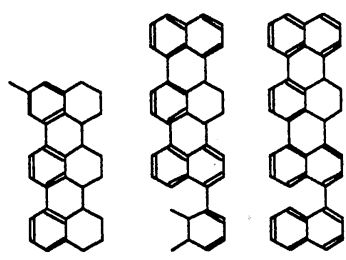

naphthalene

the residual product, and industrial development of mesophase pitch fiber and perspective understanding and application of the mesophase pitch had been very restricted. The present author and Mitsubishi Gas Chemical (MGC) Co. invented a simple method of preparing mesophase pitch from pure aromatic hydrocarbons, using $\mathrm{HF} / \mathrm{BF}_{3}$ as a condensation catalyst, which is recovered by distillation for repeated use ${ }^{6)}$. The preparation conditions in terms of temperature and time as well as starting monomers, can control the structure and properties of the mesophase pitch.

The characteristic features of the preparation are:

(1) Non-dehydrogenative condensation of aromatic nuclei, produces naphthenic groups by every condensation reaction. The pitch produced is thermally dehydrogenated to an extent controllable by the temperature and time of preparation. The mesophase pitch thus prepared is extraordinarily rich of naphthenic groups. Fig. 1 illustrates the scheme of naphthalene condensation catalyzed by $\mathrm{HF} / \mathrm{BF}_{3} . \quad \mathrm{AlCl}_{3}{ }^{7}$ ) promotes similar reactions, although the former catalyst is much more active. $\mathrm{AlCl}_{3}$ is hardly recovered and contaminates fatally the pitch as a precursor of the carbon fiber of high performance.

(2) The mesophase pitch reflects the structure of the starting monomer, a variety of properties being controlled by the monomer. In addition to homopolymers from single species of monomer, alternative and block copolymers can be designed from combinations of monomers.

(3) HF works as solvent of polymerization to maintain the reaction medium as liquid phase and (to generate)

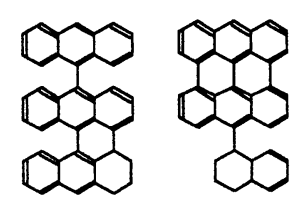

anthracene control.
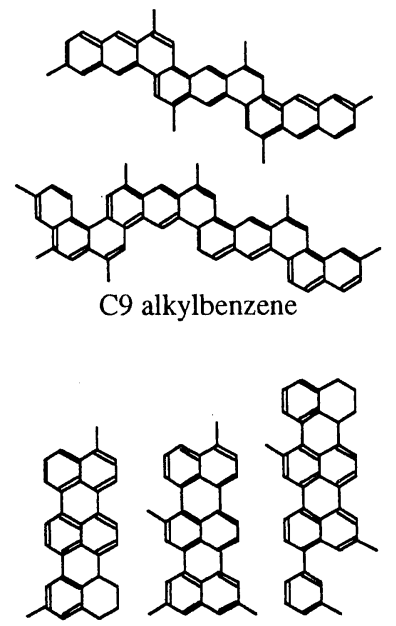

methylnaphthalene

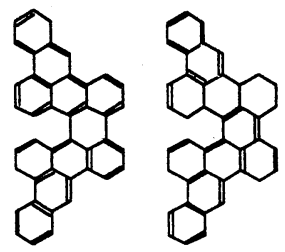

phenanthrene

Fig.2 Typical structures of mesophase pitches.

homogeneity of the products. The yield of the mesophase can be up to $90 \%$. Such features define the mesophase synthesis as a catalytic polymerization rather than the pyrolytic carbonization more difficult to

MGC started its commercial production of 1000 t/year in March 1992. A variety of mesophase pitches are now available at a price of $\$ 4-10 / \mathrm{kg}$.

\section{Structure}

Structures of mesophase pitch components have been extensively analyzed by using the techniques of solvent fractionation and FD-MS, GPC, 1H and

${ }^{13} \mathrm{C}-\mathrm{NMR}$ and FT-IR. A variety of structure of soluble fractions are illustrated in Fig. $2^{6), 8}$. The structure of component molecules strongly depends on the starting substance and preparation conditions. The whole and fractions were directly analyzed by fused ${ }^{13} \mathrm{C}-\mathrm{NMR}$ and X-ray diffraction (Diamond) ${ }^{9)}$, or solubilized by 

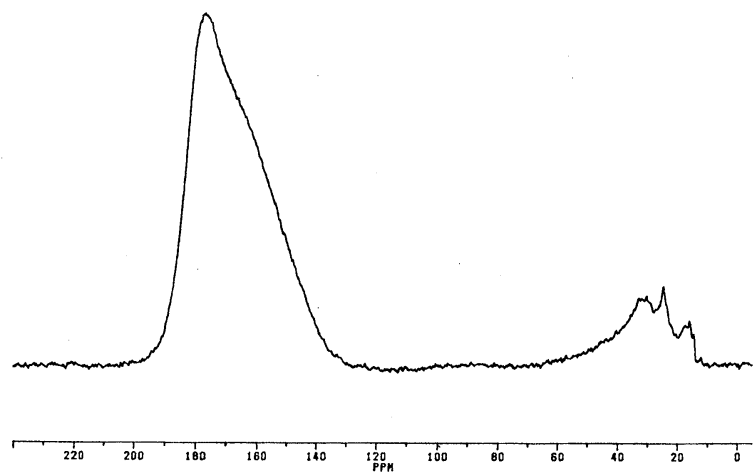

Fig.3 ${ }^{13} \mathrm{C}$-NMR spectrum of mesophase pitch catalytically prepared from naphthalene by $\mathrm{HF} / \mathrm{BF}_{3}{ }^{12)}$.

chemical modification, such as homogeneous reduction ${ }^{10)}$ and Diels-Alder reaction ${ }^{11)}$ and further analyzed as liquid products. The chemical shift in the fused ${ }^{13} \mathrm{C}-\mathrm{NMR}$ provides information of plane size of aromatic ring. Similarity and dissimilarity among the structures of the fractions are clarified.

Such structural analyses of the mesophase pitch allow a correlation of structure with properties, which suggests the control of properties by the design of mesogen molecules. The structural change of isotropic to mesophase pitches is also clarified based on analyses of a series of isotropic as well as liquid crystal pitches. The mesophase pitch derived from single species of an aromatic hydrocarbon is expected to be controlled in its properties, reflecting manners of polymerization, although it carries components of molecular weight distribution.

The molecular assembly of mesogen molecules found in the liquid crystal phase is also analyzed by fused ${ }^{13} \mathrm{C}-\mathrm{NMR}^{12)}$ and X-ray diffraction ${ }^{13)}$. Layered stacking of aromatic planes and its thermal relaxation with temperature were indicated by chemical shift of ${ }^{13} \mathrm{C}-\mathrm{NMR}$ and peak width of X-ray diffraction. Fig. 3 illustrates fused ${ }^{13} \mathrm{C}-\mathrm{NMR}$ of naphthalene mesophase pitch, which shows a resonance of $180 \mathrm{ppm}^{12)}$. The orientation of aromatic planes along the magnetic field is suggested. Dissolution of mesophase pitch in the solvent shifted the resonance to $120 \mathrm{ppm}$, as is usually observed with aromatic carbon of free rotation. The orientation appears possible only with stacked planes, and impossible with an isolated plane of even large

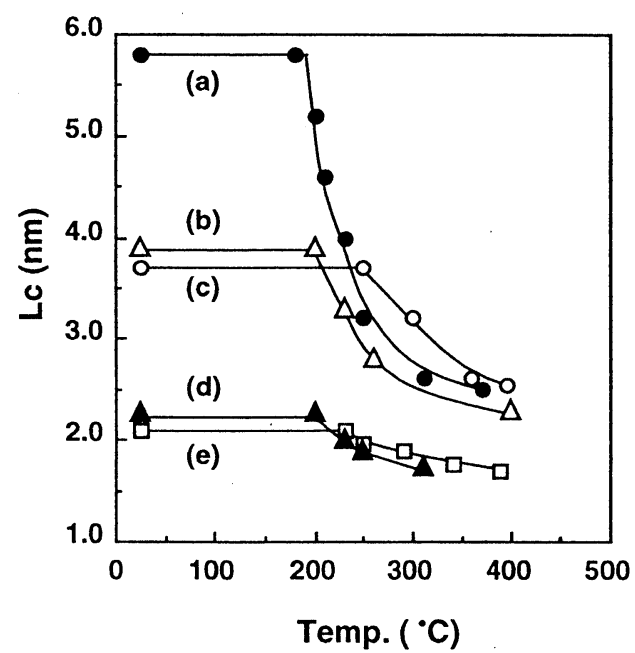

Fig.4 Lc changes of mesophase pitches at higher temperatures.

mesogen molecules in the isotropic medium. It is noted that the mesogen molecule carries some alkyl or naphthenic groups.

Mesophase pitches prepared from aromatic hydrocarbons exhibit the definite patterns of 002 diffraction, which allows the calculation of stacking height of aromatic planes. The height of stacking varied according to the temperature of measurement and constituent molecular species as shown in Fig. $4^{13)}$. High temperature loses the stacking as expected by the molecular mobility. It must be noted that the mesophase pitch exhibits the molecular ordering in its molten state, liquid crystal natures being definitely indicated.

The second point of interest is strong influences of molecular structure on the height of stacking. Methylnaphthalene derived mesophase pitch exhibited much higher stacking, of $60 \AA$ (around 18 planes), than other mesophase pitches. Degree of such stacking should influence various properties of the pitch and the molecular ordering (orientation) through the spinning in the resultant carbon fiber. Detail study on the design of constituent molecules to provide excellent properties of the carbon fibers appears very promising.

The roles of molecular structure and its distribution have been discussed in the spinning, stabilization and fiber properties to provide bases for design of mesogens in the mesophase pitch. The extent of planar 
stacking will be soon discussed to correlate the properties of carbon products. It should be noted that the stacking will be changed according to conditions

Table 2 Preparation conditions of pitches and their some properties.

\begin{tabular}{lcccccc}
\hline Sample & $\begin{array}{c}\mathrm{HF} \\
(\mathrm{mol} \%)\end{array}$ & $\begin{array}{c}\mathrm{BF} 3 \\
(\mathrm{~mol} \%)\end{array}$ & $\begin{array}{c}\text { Temp. } \\
\left({ }^{\circ} \mathrm{C}\right)\end{array}$ & $\begin{array}{c}\text { Yield } \\
(\mathrm{wt} \%)\end{array}$ & $\begin{array}{c}\text { A.C. } \\
(\mathrm{vol} \%)\end{array}$ & $\begin{array}{r}\text { S.P. } \\
\left({ }^{\circ} \mathrm{C}\right)\end{array}$ \\
\hline NP-180 & 0.67 & 0.25 & 180 & 52 & 0 & 202 \\
NP-200 & 0.81 & 0.30 & 200 & 52 & 15 & 199 \\
NP-210 & 0.83 & 0.30 & 210 & 74 & 98 & 216 \\
NP-260-1 & 0.59 & 0.15 & 260 & 71 & 95 & 219 \\
NP-260-2 & 0.30 & 0.25 & 260 & 37 & 0 & 95 \\
NP-260-3 & 0.47 & 0.20 & 260 & 68 & 100 & 212 \\
NP-300 & 0.64 & 0.10 & 300 & 58 & 100 & 285 \\
\hline AP-220 & 1.00 & 0.20 & 220 & 90 & 100 & 238 \\
AP-260 & 1.00 & 0.10 & 260 & 82 & 100 & 275 \\
\hline MNP-260 & 0.52 & 0.15 & 260 & $>80$ & 80 & 205 \\
MNP-265 & 0.52 & 0.15 & 265 & 76 & 100 & 205 \\
\hline
\end{tabular}

NP: naphthalene derived pitch.

AP: anthracene derived pitch.

MNP: methylnaphthalene derived pitch.

The amount of aromatic hydrocarbon: $1 \mathrm{~mol}$.

Preparation time is $4 \mathrm{hr}$ except for MNP-265(5 hr)

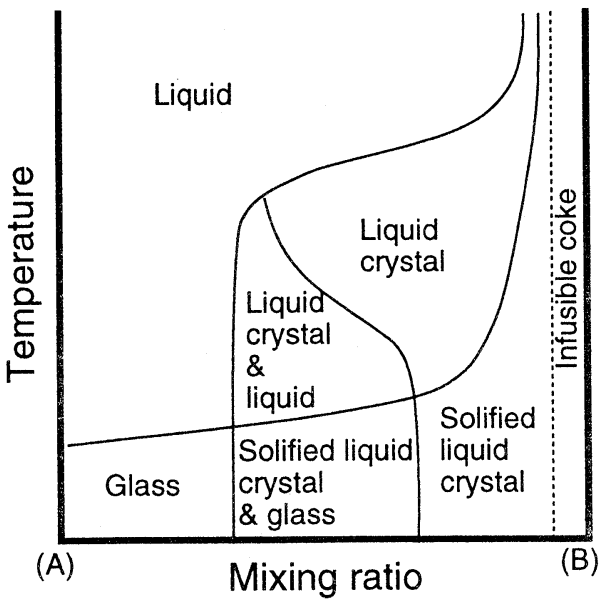

Fig.5 A Phase diagram of cooperating liquid crystal. A: isotropic fusible fraction, B: Anisotropic infusible fraction. such as temperature, pressure, and shear.

\section{Properties}

\subsection{General properties of mesophase pitch derived from aromatic hydrocarbons}

Table 2 summaries the preparation conditions and some properties of the mesophase pitches from aromatic hydrocarbons. The mesophase pitches exhibit $100 \%$ of anisotropy, melting points of $200-300{ }^{\circ} \mathrm{C}$, coke value of around $90 \%$ and melt viscosity at temperatures higher than softening points from 50 to 3000 poise. The mesophase pitches can provide a wide range of properties, maintaining $100 \%$ anisotropy.

\subsection{Liquid crystal behaviors}

Mesophase pitch exhibits properties characteristic of both thermotropic and lyotropic liquid crystals. Temperatures of glass transition, softening, spinning, phase inversion as well as the change of fluid viscosity with temperature, are measured to define its thermotropic nature. The values obtained were found strongly influenced by the molecular structure and its size distribution or composition, indicating its lyotropic nature. Fig. 5 illustrates the phases of a cooperating liquid crystal mesophase pitch. The fusible isotropic, fusible anisotropic and infusible anisotropic components, cooperatively form a liquid crystal, of which the anisotropic properties are defined by their composition as well as the respective components.

Flow or visco-elastic properties of the mesophase pitches are one of most important properties in fiber manufacturing, spinning stability, fiber shape and molecular ordering. Although not many researches have been attempted to clarify the properties in relation to their structural factors, the mesophase pitch has been reported to both Newtonian and non-Newtonian according to the constituent molecules, temperature of measurement, and range of shear rate as shown by several examples in Fig. 6 $^{14)}$. As a liquid crystal, the stacking of planar molecules to form the cluster $(\sim 10$ $\mathrm{nm})$ and micro-domains $(\sim 100 \mathrm{~nm})$ as the sub-units of molecular assembles, isochromatic domains $(0.1 \sim 100$ $\mu \mathrm{m})$ and their deformation according to the temperature and shear are expected to influence the flow properties.

\subsection{Oxidation reactivity of mesophase pitch}

Reactivity with oxygen is extensively studied in relation to the stabilization stage of the carbon fiber 


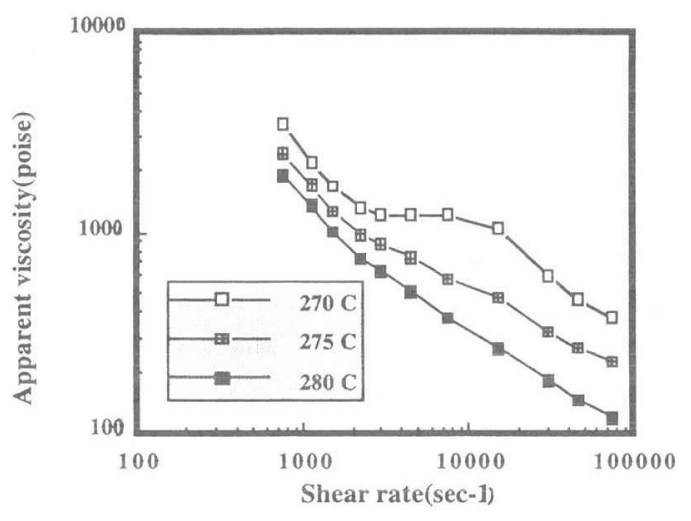

*1 Capillary: $0.2 \mathrm{~mm} / 0.2 \mathrm{~mm}$ (diameter/length)

a Viscosity vs, shear rate curves of $\mathrm{mNP}$ (Dimension of capillary: $0.2 \mathrm{~mm} / 0.2 \mathrm{~mm}$ (length/diameter))

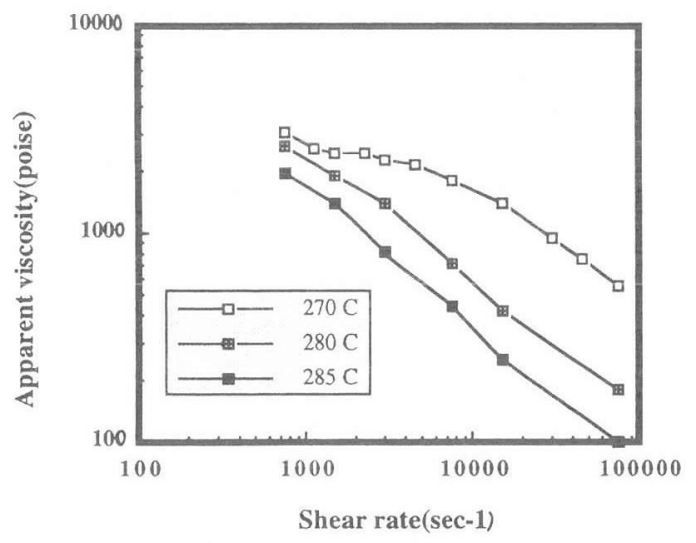

b Viscosity vs. shear rate curves of NP

(Dimension of capillary: $0.2 \mathrm{~mm} / 0.2 \mathrm{~mm}$ (length/diameter))

Fig.6 Viscosity and shear rate correlations of mesophase pitches derived from methylnapthalene and naphthalene.

and composite production. Changes in its chemical structure, solubility, and softening points as well as the kinetics of oxygen uptake, and diffusion in the fiber during the stabilization are extensively studied ${ }^{15), 16)}$ Methyl, naphthenic and isolated aromatic C-H groups accelerate the stabilization of the mesophase pitch ${ }^{17}$. They initiate the oxidation reaction. Molecular size of the component may also be influential, since the stabilization is objected to introduce non-fusibility to the pitch.

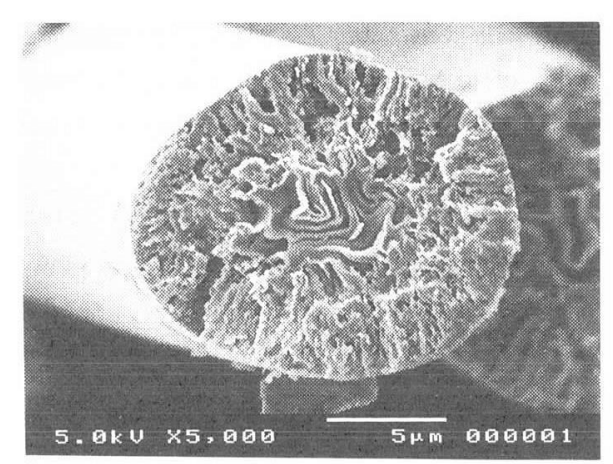

Fig.7 Scanning electron micrograph of fiber with the skin-core structure.

The structure of sufficiently and necessarily stabilized fiber is not clarified, although both insufficient and excess stabilization deteriorate the properties. Skin-core structure has also been intentionally introduced in the carbon fiber by the control of the oxidation and successive carbonization, providing new types of carbon fiber. Fig. 7. illustrates a mesophase pitch based carbon fiber of skin-core structure which was prepared by the stabilization with $10 \% \mathrm{O}_{2}$ in $\mathrm{N}_{2}{ }^{18)}$. Carbonization of such a fiber under strain gave a carbon fiber of improved strength. Hollow carbon fiber has been prepared by the carbonization of skin-stabilized fiber ${ }^{18 a)}$.

The combination of oxidation and solvent extraction quickens the stabilization process, indicating the significance of the stabilization ${ }^{19)}$.

\section{Spinning properties of mesophase pitch}

Spinning of the mesophase pitches carries two problems, spinning stability, and control of size, shape, and molecular alignment of spun fiber. The first problem has been considered to be most influenced by high purity free from solid contaminant, gel substances of mesophase pitch, content of volatile matters, and temperature-viscosity and shear-viscosity correlations. The second problem is strongly influenced by the molecular weight distribution, and molecular assemble structure in the mesophase pitch.

AR mesophase pitch has been reputed to have excellent spinning properties even if it exhibits rather steep temperature-viscosity correlation.

Spinning and control of molecular orientation in 

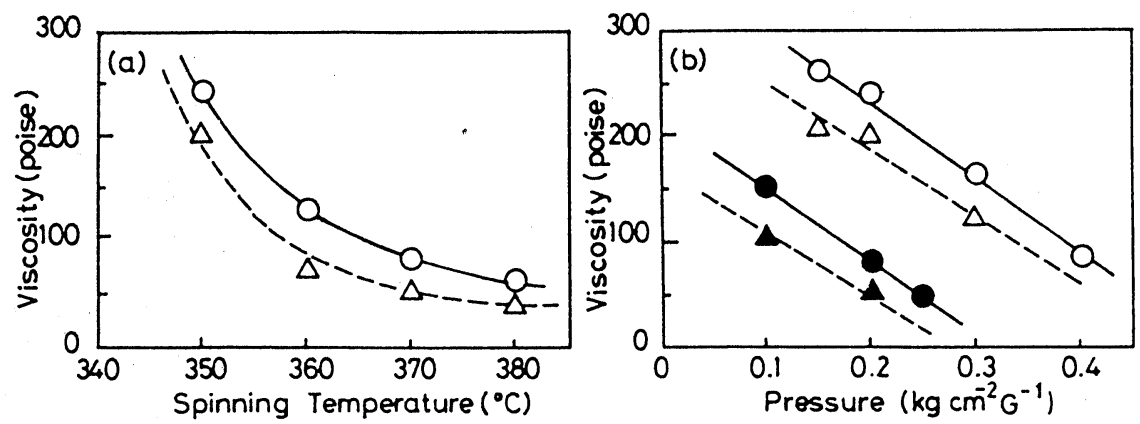

Fig.8 Change of viscosity of mesophase pitch and its blend with PVC-pitch at variable temperature, a) Variable temperature and b) Variable pressure.

((a) Applied pressure: $0.2 \mathrm{~kg} / \mathrm{cm} 2 \mathrm{G},(\bigcirc) \mathrm{MP},(\triangle) \mathrm{PVC}-10$. (b) Spinning temperature: $\left.350^{\circ} \mathrm{C},(\bigcirc) \mathrm{MP},(\triangle) \mathrm{PVC}-10 ; 370^{\circ} \mathrm{C},(\bigcirc) \mathrm{MP},(\Delta) \mathrm{PVC}-10\right)$.

the pitch fiber are examined extensively to control the transverse texture of carbon fiber for higher performance ${ }^{20)}$. Spinning conditions, nozzle shape, molecular structure and assembly or composition of mesogens appear influential through the viscosity of mesophase pitch, shear in the nozzle, height of the layered stacking in the sub-units. Although there are many important techniques accumulated in the production of carbon fibers. Most of them remain at the state of art on a very empirical bases. Scientific data to define the mesophase pitches are necessary for a progress to the next stage of marked advances.

The mesophase pitch has been proved to show die-swelling at the outlet of the nozzle ${ }^{21)}$. The extent depends on the temperature, mesophase species, and orientation achieved in the nozzle. Such flow properties of the mesophase pitch are expected to influence the shape, molecular alignment, and properties of the as-spun fiber ${ }^{22}$. The correlation between structures (molecular shape and stacking) and flow properties of mesophase pitch is now most wanted to be clarified. A variety of mesophase pitches in terms of molecular size, shape, and substituents now supplied may establish a new field of oligomeric liquid crystals.

\section{Modifications of mesophase pitch}

Mesophase pitch prepared by the catalytic method can be modified further chemically and physically. Molecular structure of mesogens is changed by addition, substitution, and oxidation. High solubility of the mesophase pitch allows the reactions in the homogeneous liquid phase. The catalyst should be carefully selected not to contaminate the resultant mesophase pitch. Hydrogen transfer reaction has been widely examined ${ }^{23)}$. Thermal and catalytic Diels-Alder reactions attract interests for changing the structure of mesogen molecules ${ }^{24)}$. Less soluble fractions in the mesophase pitch were effectively solubilized by such reactions. Sterically hindered structure after the reaction is most interesting to know how the molecular assembly and the properties of the mesophase pitch and its derived carbon are modified.

Introduction of functional groups at the terminal positions of mesogen molecules is also possible. Hydroxyl, carbonyl, carboxyl and amino groups on the aromatic ring can modify extensively the interactive forces of the mesophase pitch with solids or intermolecular interaction.

The lyotropic natures of the mesophase pitches suggest physical control of its properties by blending monomeric liquid crystal, isotropic and anisotropic pitches, and polymers. The blending controls viscosity, reactivity for stabilization, and stacking of mesophase pitches, maintaining the liquid crystal nature ${ }^{25)}$. Fig. 8 illustrates influences of blending on the viscosity of the mesophase pitch which controlled the transverse texture of the carbon fiber $^{26)}$. Molecules located at the interlayer positions of stacked mesogens modify the viscosity and stacking order.

The oxidation may initiate at the most reactive sites to enhance the reactivity of the whole pitch through the activation of the oxidants or reacting with 
surrounding molecules. Enhanced reactivity for the stabilization by blending is indicated in Table $3^{27)}$.

Finally, linear polymers of large molecular weight are expected to strengthen the fiber form of mesophase pitch before the oxidative stabilization, distributing homogeneously or islands-like in the mesophase pitch. Blending of liquid crystal polymers to produce

Table 3 Enhanced stabilization reactivity by blending PVC pitch.

\begin{tabular}{lcc}
\hline & $\begin{array}{c}\text { Temperature } \\
(\text { C })\end{array}$ & $\begin{array}{l}\text { Stabilization } \\
\text { Time }\end{array}$ \\
\hline MP & 230 & $9 \mathrm{~h}$ \\
PVC-10 & & $6 \mathrm{~h}$ \\
MP & 270 & $120 \mathrm{~min}$ \\
PVC-5 & & $80 \mathrm{~min}$ \\
PVC-10 & & $60 \mathrm{~min}$ \\
MP & 300 & $15 \mathrm{~min}$ \\
PVC-10 & & $12 \mathrm{~min}$ \\
\hline
\end{tabular}

polymeric liquid crystal alloys is being investigated. For example, Fig. 9 illustrates a model of a mesophase pitch fiber blended with $\mathrm{PPO}^{28}$.

Some thermosetting polymers such as phenolic or epoxy resins are blended to the mesophase pitch to emphasize the adhesive force of the pitch ${ }^{29)}$.

\section{8. high performances of mesophase pitch based carbon fibers}

Mesophase pitches derived from aromatic hydrocarbons have been evaluated as excellent precursors for the carbon fibers of high performance. They are easily spun, stabilized, carbonized and graphitized even in the university laboratory. Our laboratory has prepared a number of carbon fibers to find factors to improve the performances. We have reported that the mesophase pitch provides very high modulus above $8 \times 10^{4} \mathrm{~kg} / \mathrm{mm}^{2}$ by graphitizing the fibers at $2500^{\circ} \mathrm{C}$. The high tensile strength is still a
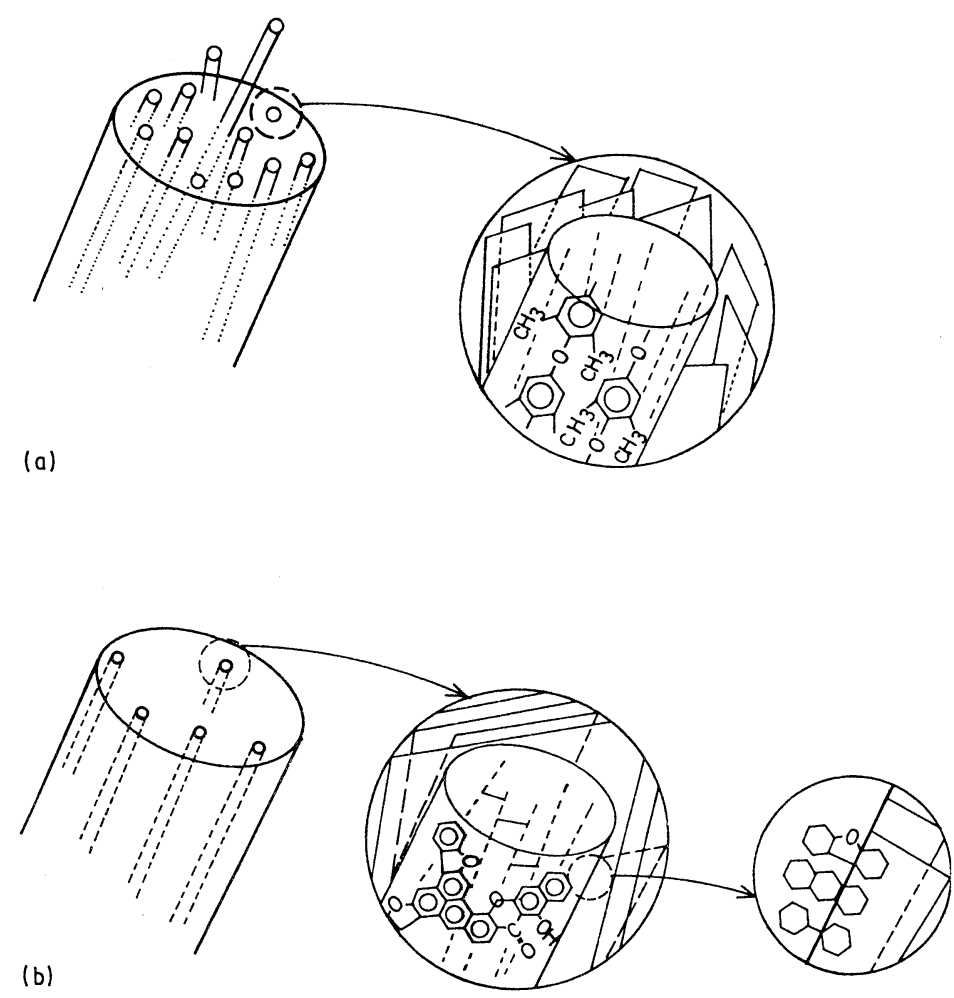

Fig.9 Model for composite fiber(Mesophase pitch and poly(phenylene oxide)). 
target for extensive research. First of all, the highest strength of $410 \mathrm{~kg} / \mathrm{mm}^{2}$ was obtained by the optimizing the stabilization conditions ${ }^{30), 31 \text {. }}$.

Spinning of naphthalene and methylnaphthalene derived mesophase revealed that the latter pitch provided higher order of alignment in the spun fiber, suffering large open-wedge in the particular temperature range, which allowed further higher modulus ${ }^{32}$.

Compressive strength of carbon fiber, especially the mesophase pitch based one, is recognized to be most wanted to be improved. Fig. 10 illustrates various transverse shapes and textures of carbon fibers which were prepared by spinning at various temperatures through non-circular nozzles ${ }^{33}$. The circular shape fibers spun through non-circular nozzle show radialonion textures by spinning in the low viscosity range.
Thus, non-circular nozzles spinning at the appropriate temperature is one of procedures to control the transverse texture, which is believed to influence strongly the mechanical properties of resultant carbon fiber ${ }^{34)}$. Table 4 summarizes mechanical properties of some carbon fibers.

The careful spinning of selected mesophase pitch of high purity through appropriate nozzle, stabilization, carbonization and graphitization allow the carbon fiber of excellent performances, tensile strength and compressive strength above 600 and $200 \mathrm{~kg} / \mathrm{mm}^{2}$, respectively.

Die swell phenomena are suggested as described above. At lower temperatures, shape of fiber is defined by that of the nozzle, however it becomes deformed into rod shape at higher spinning

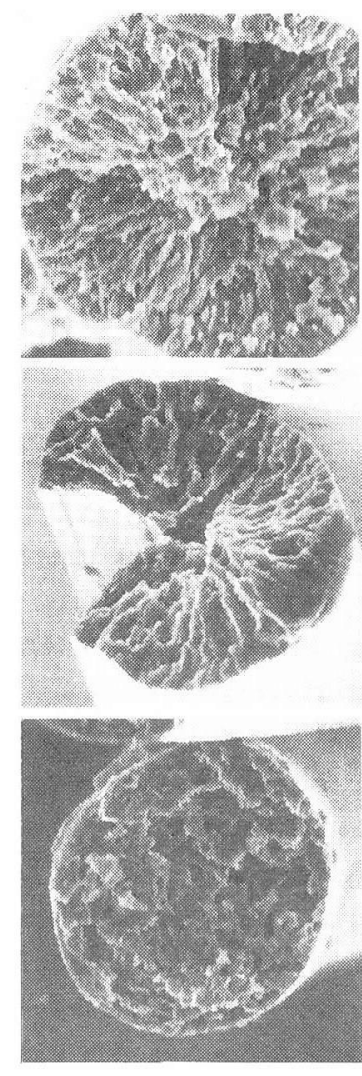

ROUND
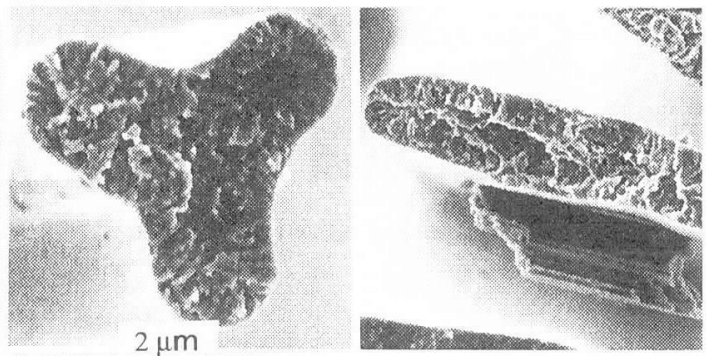

275
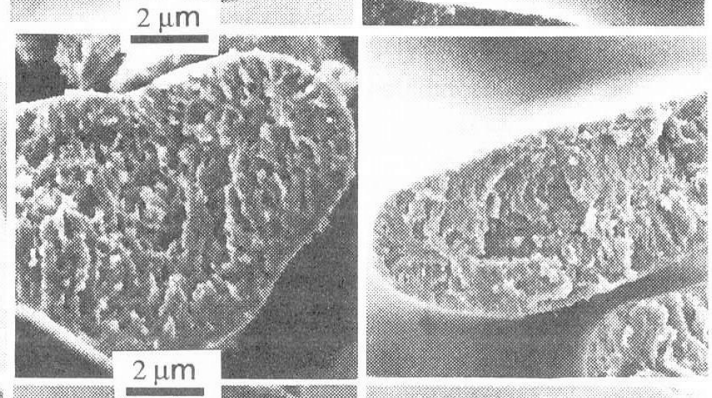

285

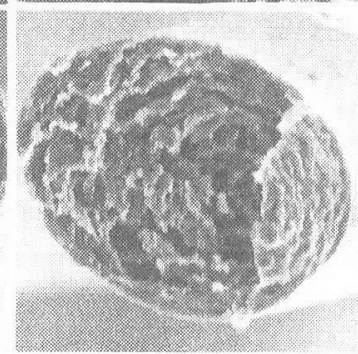

295

Fig.10 Transverse shapes and textures of carbon fibers spun with circular, Y, and slit shaped spinning nozzles. 
Table 4 Mechanical properties of graphitized fibers.

\begin{tabular}{c|c|cccc|cccc}
\hline $\begin{array}{l}\text { Shape of } \\
\text { fiber }\end{array}$ & Code & $\begin{array}{c}\mathrm{D}^{\mathrm{a}} \\
\mu \mathrm{m}\end{array}$ & $\begin{array}{c}\mathrm{S}^{\mathrm{b})} \\
\mu \mathrm{m}^{2}\end{array}$ & $\begin{array}{c}\mathrm{l}^{\mathrm{c})} \\
\%\end{array}$ & $\begin{array}{c}\mathrm{Lc} \\
\mathrm{nm}\end{array}$ & $\begin{array}{c}\text { T.S. } \\
\mathrm{kg} / \mathrm{mm}^{2}\end{array}$ & $\begin{array}{c}\text { Y.M. } \\
\mathrm{kg} / \mathrm{mm}^{2}\end{array}$ & $\begin{array}{c}\text { C.S. } \\
\mathrm{kg} / \mathrm{mm}^{2}\end{array}$ \\
\hline \multirow{2}{*}{ Tape } & t-mNA-270-no & $2.9 / 14.5$ & 43 & 0.45 & 17 & 385 & $9.0 \times 10^{5}$ & 71 \\
& t-mNA-270-20 & $2.5 / 12.8$ & 32 & 0.37 & 13 & 332 & $8.9 \times 10^{5}$ & - \\
\hline Circular & c-mNA-275-no & 7.0 & 39 & 0.35 & 21 & 266 & $7.2 \times 10^{5}$ & 58 \\
\hline
\end{tabular}

a) Diameter, b) Cross-sectional area, c) Strain to break, d) Tensile strength,

e) Young's modulus, f)Compressive strength(tested by composite method).

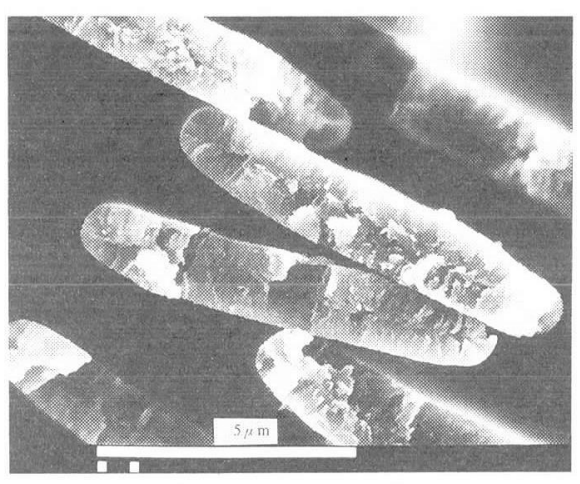

Fig.11 SEM photograph of carbon tape graphitized at $2500{ }^{\circ} \mathrm{C}$.

temperatures, regardless of the nozzle shapes. It is very interesting that the methylnaphthalene derived mesophase pitch allows much more similar shapes, and aspect ratios of the fiber to those of the nozzles than the naphthalene derived mesophase pitch. As an extreme case, the authors succeeded to prepare carbon tape under $2 \mu \mathrm{m}$ thickness from a methylnaphthalene pitch as shown Fig. 11 $\mathbf{1}^{35}$. Extremely superior mechanical properties of such thin fibers should be noted.

\section{Applications of mesophase pitch}

Several industries have begun the manufacture of the carbon fiber from naphthalene derived mesophase pitch prepared with $\mathrm{HF} / \mathrm{BF}_{3}$. Excellent properties, and reasonable cost, are characteristics of the mesophase $\operatorname{pitch}^{36)}$. We are at the final stage to control the properties of the mesophase pitch suitable for the multihole spinning. More varieties of mesogens by designing the starting aromatic hydrocarbons are expected to allow better and broad performances of carbon fibers.

Activated carbon fibers have been commercialized. Their unique pore structure allows rapid adsorption and desorption for maximum use of pore volume. Control of surface functional groups provided high selectivity as well as high capacity. Many applications in environmental protection have been developed ${ }^{37}$.

Application of mesophase pitch is expanding because of its reasonable cost, high carbon yield, high carbon purity, controlled viscosity in its fused state, dissolving ability of polymers, and designable terminal groups of mesogen molecules.

CFRP dominates the composite today. Better polymers of excellent properties at a reasonable cost may further expand its application. Nevertheless, carbon-carbon composite can find broader application in domestic purposes when its fabrication cost is significantly reduced.

Mesophase pitch has been recognized to the best binder for the composite. A variety of mesophase pitches prepared from aromatic hydrocarbons exhibited controllable viscosity-temperature relations ${ }^{38)}$ as proposed by White ${ }^{39)}$. The best pitch can be chosen from their large varieties. All pitches possess the high coking value and oxidation reactivity.

Chopped carbon fiber ${ }^{40)}$ or ceramic grains ${ }^{41)}$ coated with the mesophase pitch can be molded or extruded and carbonized into composites of high strength. The pitch penetrates freely into cloths and weaves of carbon fiber, being rapidly oxidized or slightly carbonized into the thermosetting form with maintaining adhesive forces. carbon fiber-mesophase pitch prepreg can be prepared by controlled oxidation or heat treatment which assures the further higher carbon yield and its self-adhesion between its layers ${ }^{40)}$. 
The authors applied the mesophase pitch as binder of $\mathrm{MgO}^{42), 43)}$. Very high mechanical strength was obtained by calcination at $500^{\circ} \mathrm{C}$ where phenolic resin lost binding strength. Control of grain size of $\mathrm{MgO}$, application of phenyl resin as an additive at its proper amount, and homogeneous distribution of grains improved the strength of the composite at $900-1300{ }^{\circ} \mathrm{C}$. Practical application in steel industry is now in progress. Enhanced adhesive force of the mesophase pitch through the stabilization eliminates necessity of phenolic resin.

Carbonaceous mesophase spheres of uniform diameter around $1 \sim 10 \mu \mathrm{m}$ have been proved to have unique properties and applications such as precursors for high density and high strength carbon materials, stable spherical packing-substances, catalyst support and active carbon. The authors found that the emulsion of around $10 \mu \mathrm{m}$ diameter is derived from the mesophase pitch to be suspended in water. Isolated spheres are oxidized and stabilized ${ }^{44}$.

Extremely high aromaticity provides thermal stability to the mesophase pitch, allowing its application as thermo-resistive lubricant ${ }^{45}$.

Finally, particular aromatic planes of large size can be isolated from the mesophase pitch to be the precursors of the functional molecules for electronic, magnetic, and photo-electric application. Otani proposed ferromagnetic carbons by using stabilized radical in adjacent of large aromatic planes ${ }^{46)}$.

\section{Future expectation}

Much broader varieties of mesophase pitches can be designed by controlling precisely the structure and polymerization of aromatic molecules. They are expected to develop its more desirable properties for its broader and excellent application.

Mesophase pitch can be an interesting objective in material sciences of broad disciplines. Its structural resolution and molecular design are areas of organic and polymer chemistry. Its molecular ordering and physical properties such as electric and thermal natures, flow mechanics and photo-electronic behaviors are solved by physical chemistry and physics. I expect by this chance participation of many scientists in the material science of the mesophase pitch, an unique substance.

\section{Acknowledgment}

The author acknowledge his co-workers Dr. Korai, Toshima, Shimizu, Zen, Yoon, Mr. Fujiura, Kanno, and Sakai, Fujiyama and Komatsu for their patient struggles with the fascinating mesophase pitches.

\section{References}

1) J. D. Brooks and G. H. Taylor, Chemistry and Physics of Carbon, ed. by P. L. Walker Jr., Vol. 4, Marcel Dekker, New York, 243, (1968).

2) S. Otani, Laid-open Japanese Patent Application, 49-8634 (1974).

3) L. S. Singer, Carbon, 16 (1978) 408.

3a) Y. D. Dark and I. Mochida, Carbon 27 (1989) 925.

4) R. J. Diefendorf, UK Patent GB2005298A (1979).

5) H. Honda and Y. Yamada, Japanese Patent 5818421.

5a) I. Mochida, K. Kudo, N. Fukuda, K. Takeshita, and R. Takahashi, Carbon 13 (1975) 135.

6) I. Mochida, K. Shimizu, Y. Korai, H. Otsuka, Y. Sakai, S. Fujiyama, Carbon 28 (1990) 311.

7) I. Mochida, E. Nakamura, K. Maeda and K. Takeshida, Carbon 14 (1976) 123.

8) a) Y. Korai, M. Nakamura, I. Mochida, Y. Sakai and S. Fujiyama, Carbon 29 (1991) 561; b) I. Mochida and Y. Korai, "Petroleum Derived Carbon", Vol. 2, American Chemical Society, (1986) p.29.

9) R. Diamond, Acta Crypt. 10359 (1957).

10) L. Reggel and I. Wender, Fuel 43 (1965) 143.

11) I. Mochida, H. Toshima, Y. Korai and T. Hino, $J$. Mater. Sci., in press.

12) T. Nishizawa, and M. Sakada, Carbon 30 (1992) 147.

13) Y. Korai and I. Mochida, Carbon 30 (1992) 1019.

14) S. H. Yoon, Y. Korai and I. Mochida, Carbon 32 (1994) 273.

15) I. Mochida, H. Toshima, Y. Korai and T. Hino, $J$. Mater. Sci. 24 (1989) 389.

16) I. Mochida, H. Toshima, Y. Korai and T. Matsumoto, Chemi. Lett (1987) 2279.

17) I. Mochida, A. Azuma, Y. Korai, M. Kakuta, and E. Kitajima, J. Mater. Sci. 26 (1991) 4836.

18) I. Mochida, S. M. Zeng, Y. Korai, T. Hino and $H$. 
Toshima, Carbon 29 (1991) 23.

18a) Y. Arai and N. Tomioka, Ext. Abs. 18th Annual Meeting, Carbon Society of Japan (1991) 1 C06

19) Y. D. Park and I. Mochida, Carbon 26 (1988) 375.

20) T. Matsumoto, Pure \& Appl. Chem. 57 (1985) 1553.

21) S. H. Yoon, Doctor thesis, Kyushu University (1994) p.117.

22) S. H. Yoon, Y. Korai and I. Mochida, Carbon 32 (1994) 273.

23) Y. Yamada, Ext. Abs. 10th Annual Meeting, Carbon Soc. Japan (1988) p.16.

24) H. Toshima, H. Hino, and I. Mochida, J. Mater. Sci. in press.

25) I. Mochida, H. Toshima, Y. Korai and T. Matsumoto, J. Mater. Sci. 23 (1988) 670.

26) I. Mochida, H. Toshima, Y. Korai and T. Matsumoto, J. Mater. Sci. 24 (1989) 57.

27) I. Mochida, H. Toshima, Y. Korai and T. Matsumoto, ibid. (1989) 2279.

28) I. Mochida, H. Toshima, Y. Korai, and T. Naito, J. Mater. Sci. 23 (1988) 678.

29) I. Mochida, K. Koike, and Y. Korai, Carbon, to be submitted.

30) S. H. Yoon, Y. Korai, and I. Mochida, Carbon 32 (1994) 281.

31) Y. Mochida, L. Ling and Y. Korai, J. Mater. Sci. in press

32) Y. Mochida, S. H. Yoon, N. Takano, and Y. Korai, Ext. Abs. 20th Annual Meeting, Carbon Soc. Japan (1993) p.88.
33) I. Mochida, S. H. Yoon and Y. Korai, J. Mater. Sci. 28 (1993) 2331.

34) I. Mochida, S. H. Yoon, and Y. Korai, Proceedings of International Symposium on Carbon (Essen1992) p.848.

35) I. Mochida, S. H. Yoon and Y. Korai, J. Mater. Sci. 28 (1993) 2135.

36) I. Mochida, K. Shimizu, Y. Korai, S. H. Yoon, and R. Fujiura, TANSO 1992 [No.155] 370.

37) I. Mochida, T. Hirayama, S. Kisamori, S. Kawano and H. Fujitsu, Langmuir 8 (1992) 2290.

38) R. Fujiura, T. Kojima, K. Kanno, Y. Korai, and I. Mochida, Carbon 31 (1993) 97.

39) J. L. White, M. K. Gopalakrishnan, and B. Fathollahi, Carbon 32 (1994) 301.

40) I. Mochida, R. Fujiura, and Y. Korai, TANSO 1992 [No.150] 398.

41) I. Mochida, N. Akashi and Y. Korai, Proceedings of International Symposium on Carbon (Paris, 1990) p.292.

42) I. Mochida, Y. Korai, N. Akaishi, R. Fujiura, and K. Ito, TANSO 1991 [No.149] 256.

43) I. Mochida, S. Koike, Y. Korai, K. Kanno, and K. Kojima, Proceedings of Internation Symposium on Carbon (Granada, 1994) in press.

44) S. H. Yoon, Y. D. Park and I. Mochida, Carbon 30 (1992) 781.

45) Y. Tomari, I. Mochida, and M. Iino, J. Janpanese Society of Tribologists 38 (1993) 1097.

46) M. Ota, S. Otani, K. Kobayashi, A. Kojima and E. Ota, Ext. Abs. 55th Annual Meeting on Chemistry, Chemical Society of Japan, (Sendai, 1988) p. 681. 